\title{
Integrated Cost and Schedule Control Systems for Nuclear Power Plant Construction: Leveraging Strategic Advantages to Owners and EPC Firms
}

\author{
Youngsoo Jung, ${ }^{1}$ Byeong-Suk Moon, ${ }^{2}$ Yun-Myung Kim, ${ }^{3}$ and Woojoong Kim ${ }^{2}$ \\ ${ }^{1}$ College of Architecture, Myongji University, Yongin 449-728, Republic of Korea \\ ${ }^{2}$ Central Research Institute, Korea Hydro \& Nuclear Power Co., Ltd., Daejeon 305-343, Republic of Korea \\ ${ }^{3}$ Project Management Department, KEPCO Engineering and Construction Company, Inc., Yongin 446-713, Republic of Korea
}

Correspondence should be addressed to Youngsoo Jung; yjung97@mju.ac.kr

Received 3 December 2014; Accepted 8 February 2015

Academic Editor: Alejandro Clausse

Copyright (C) 2015 Youngsoo Jung et al. This is an open access article distributed under the Creative Commons Attribution License, which permits unrestricted use, distribution, and reproduction in any medium, provided the original work is properly cited.

As the owners expect that the cost and time for nuclear power plant construction would decrease with new entrants into the market, there will be severer competition in the nuclear industry. In order to achieve performance improvement and to attain competitive advantages under the globalized competition, practitioners and researchers in the nuclear industry have recently exerted efforts to develop an advanced and efficient management methodology for the nuclear mega-projects. Among several candidates, integrated cost and schedule control system is of great concern because it can effectively manage the three most important project performances including cost, time, and quality. In this context, the purpose of this paper is to develop a project numbering system (PNS) of integrated cost and schedule control system for nuclear power plant construction. Distinct attributes of nuclear power plant construction were investigated first in order to identify influencing variables that characterize real-world implementation of advanced cost and schedule controls. A scenario was then developed and analysed to simulate a case-project. By using this case-project, proposed management requirements, management methods, measurement techniques, data structure, and data collection methods for integrated cost and schedule PNS were illustrated. Finally, findings and implications are outlined, and recommendations for further research are presented.

\section{Introduction}

Due to recent new entrants into the nuclear construction industry, it was reported by Richardson [1] that "the nuclear industry is rapidly globalizing. As it does so, there will be sharper vendor competition. Cost and construction time are expected to fall, and more countries will opt for nuclear power." Under this globalized intense competition, owners and companies in the nuclear industry strive to enhance the quality, cost, and time for nuclear construction projects.

Effectively managing three major performances of quality, cost, and time is the utmost objective for any construction project. It is known that, up to date, the most advanced and systematic method for managing these three performances in an integrated way is "earned value management system" (EVMS). However, additional management effort required to collect and maintain detailed data for EVMS has been highlighted as a major barrier to utilizing this concept over a quarter of a century [2-4]. This argument is especially factual for a nuclear power plant (NPP) construction project due to its gigantic size and distinct complexity. In order to maximize the benefits that this integration has to offer, methodologies, techniques, and tools to reduce the workloads for integrated cost and schedule control should be investigated in a comprehensive manner. Nevertheless, there has been no previous research addressing these issues for nuclear power plant (NPP) construction. Furthermore, there has been no legitimate study that proposed a comprehensive EVMS numbering system encompassing project life cycle.

In this context, the purpose of this paper is to develop a methodology of formulating project numbering system (PNS) for nuclear power plant construction EVMS. A welldefined PNS not only effectively optimizes EVMS workloads for on-going projects but also significantly improves 
the reusability of historical database for future projects. Therefore, proposed PNS in this study is not intended to merely serve as a numbering system for data manipulation; it is rather developed to enhance organizational competence by automatically accumulating knowledge extracted from on-going and historical project database. In other words, technical issues should be thoroughly analysed with business process reengineering (BPR) emphasis in order to improve EVMS viability.

Distinct characteristics of NPP construction including participants, project size, lifecycle, project delivery method, and other managerial requirements were studied first in order to identify real-world EVMS PNS requirements. An NPP case-project was then developed with a scenario for the purpose of formulating and illustrating the proposed PNS in this study with complete details. Research objectives were also set within this scenario. Even though the scenario is case specific, common conditions for typical NPP construction were fully considered to generalize the PNS model. Finally, EVMS policies, management methods, and progress measurement techniques for NPP EVMS were briefly presented. Effectiveness and viability of the proposed system were examined by applying to the case-project. This paper outlines the result of an "action research" to test EVMS applicability to NPP, as the authors have conducted an experiment of information systems (IS) planning for an organization-wide NPP EVMS system.

\section{Earned Value Management Systems (EVMS)}

Cost, schedule, and quality are the three major performance indicators for construction organizations and projects. Monitoring and managing these three performances provide the project managers with valuable information in terms of "current status, corrective countermeasure, and forecast of future risks." Among these three indicators, cost and schedule are closely interrelated in terms of sharing common data for the performance assessments [4]. Therefore, benefits from integrating cost and schedule control (i.e., EVMS) have been asserted by numerous researchers and practitioners ever since this idea was first promoted in the 1960s [6-8]. However, the excessive management demands of collecting and maintaining detailed data have been highlighted by previous research as the major barrier to utilizing this concept over a quarter of a century [2-4].

2.1. Control Account (CA). The basic concept of EVMS utilizes focal points for the integration of scope, cost, and schedule. A control account (CA) in EVMS acts for "a management control point at which budgets and actual costs are accumulated and compared to earned value for management control purposes" and represents "the work assigned to one responsible organizational element" [9]. Therefore, the CAs are used as activities in a network schedule, as work packages for the project budget, and as packages for progress payment at the same time $[6,7]$. Namely, the basic role of CA is the common denominator and focal point for the integration of scope, cost, and scheduling.
Determining the level of details for CAs is a key decision for effective EVMS implementation [10]. A higher level CA (with less detail) dramatically alleviates the managerial overhead effort, but it is difficult to retain precise information for cost and schedule engineers. Trade-off in between workloads and details needs to be analysed based on the project characteristics and managerial requirements. In order to select the most efficient CAs for EVMS, the whole scope of NPP construction project must be defined in a hierarchical and systematic breakdown structure.

2.2. Work Breakdown Structure (WBS). Work breakdown structure (WBS) is defined as "a deliverable-oriented grouping of project elements, which organizes and defines the structure of the entire project." "Each descending level represents an increasingly detailed definition of a project component" [11]. Fleming and Koppleman [8] maintain that "the WBS provided an opportunity for all key functions on a project to view the project in the same manner, to speak a common project language for the first time." Due to this importance of WBS, CII [12] recently exerts research efforts to develop "enhanced work packaging" or "advanced work packaging" to utilize the best practices in this area.

For advanced usage of WBS, Jung and Woo [4] stressed that "the significant characteristics of WBS in project control are twofold; one is its classifying mechanism that decomposes the project elements into a manageable level, another is its integrating mechanism that provides a common perspective to relevant construction business functions." Selected WBS packages serve as CAs for EVMS where cost and schedule are integrated.

WBS formulation for NPP construction projects is a daunting task as it should encompass every single work package and cost item throughout the entire project life cycle (i.e., planning, design, procurement, construction, start-up, and even operating/maintenance) of a mega-project. On the other hand, to some extent, it is also true that WBS for NPP can be easier to handle from a project management organization's (PMO) perspective, because of limited number of prime engineering firms, equipment suppliers, and contractors with highly competitive technical capabilities.

2.3. Project Numbering System (PNS). For the purpose of systematic communication and integration of project information, a project numbering system (PNS) prescribes standard procedures and methods to number all different types of data and documents within a project. Every single document, drawing, specification, equipment, schedule activity, cost item, or inspection must be assigned with a unique number so that each can be clearly identified. Due to the complexity of project information, a construction PNS normally requires two basic components: a "standard classification" and a "sequencing structure." As an example, a schedule activity of concrete work (C0300) for a footing (E0100) can be numbered as C0300E0100. In this simple example, C0300 is a standard classification number for concrete "commodity" whereas E0100 is the standard number for footing "element." It is noteworthy that this example has set a standard numbering sequence for schedule activities. Namely, in this example, 
TABLE 1: EVMS implementation cases.

\begin{tabular}{|c|c|c|c|c|}
\hline Description & Project $A^{a}$ & Project $\mathrm{B}^{\mathrm{b}}$ & Project $C^{c}$ & Project $\mathrm{D}^{\mathrm{d}}$ \\
\hline Interview date & September 2010 & November 2010 & November 2010 & March 2013 \\
\hline Industry & Defense & Nuclear power plant & Civil infrastructure & Housing (Hanok) \\
\hline Participants & Limited & Limited & Limited & Many and unspecified \\
\hline Project type & $\mathrm{R} \& \mathrm{D}+$ production & $\mathrm{E} / \mathrm{P} / \mathrm{C} / \mathrm{M}$ & Construction & Construction \\
\hline Project duration & About 75 months & About 55 months & About 48 months ${ }^{\mathrm{f}}$ & About 3 months \\
\hline Project budget & 1.3 billion dollars & 20 billion dollars & 0.12 billion dollars ${ }^{\mathrm{f}}$ & 200,000 dollars \\
\hline Delivery method & Multiprime & DBM & DBB & DBB \\
\hline Payment method & Cost reimbursable & Lump-sum & Total cost with unit price & Total cost with unit price \\
\hline Progress measurement & $\begin{array}{l}\text { Milestone with } \\
\text { percent complete }\end{array}$ & Earned standard ${ }^{e}$ & Physical measurement & Weighted milestone \\
\hline Number of CAs (EVMS) & 136 & $1,400^{\mathrm{e}}$ & $1,000^{\mathrm{f}}$ & 50 \\
\hline Average size of CA & 956,000 dollars & $1,429,000$ dollars $^{\mathrm{e}}$ & 120,000 dollars $^{\mathrm{f}}$ & 4,000 dollars \\
\hline
\end{tabular}

the commodity number for first five digits and the element number for last five digits are assigned as a fixed sequence.

A PNS for NPP EVMS requires making the most use of existing standard classifications for cost, schedule, quality, and other management functions in order to easily integrate entire systems. Another important fact is that the PNS should effectively facilitate providing meaningful information for the managers and engineers of NPP projects. Again, leading all participants with superior knowledge as a coordinator is critical capability for an NPP PMO. Therefore, a PNS for NPP EVMS needs to be designed to achieve this managerial requirement in addition to EVMS basics.

2.4. PNS of NPP Construction EVMS. PNS data structure for EVMS may vary depending on the role of a project participant. This paper focuses on an owner's perspective for managing NPP projects. An active owner exhibits a tendency to be involved in the project both technically and managerially. A PMO (project management organization), whether it is in an owner or in an EPC's organization, has similar managerial interests and requires the same level of detail for EVMS (high level with less detail). Both an owner and an engineering/procurement/construction (EPC) PMO need to integrate many different business functions in a similar pattern throughout the project life cycle in order to handle EVMS requirements.

From an EPC firm's perspective, a capability of coordinating and integrating "planning, engineering, procurement, construction, start-up, and operation" is critical to be a PMO regardless of the fact that the firm is originally an equipment supplier or a contractor. Again, EVMS should not be designed to merely gather cost and schedule information. It should be an oversight management mechanism. PNS for NPP construction EVMS in this paper will explore solutions with this emphasis.

\section{EVMS Variables of NPP Construction Project Management}

Nuclear power plant (NPP) construction has distinct characteristics as compared to other construction projects. As discussed in Section 2, specific characteristics of a construction project directly determine the nature of CA, WBS, and PNS for EVMS. In order to examine these variations, this study initially compared four cases of real-world EVMS implementation based on possible EVMS variables identified by the authors as listed in Table 1. Even though some attributes are location specific (by local regulations and others), Table 1 provides an overview of how nuclear construction is different from other types. Based on this comparative analysis, six independent variables of NPP EVMS including "project participant, project size, delivery method, progress payment method, progress measurement method, and project management strategies" are identified as described in Table 2. Each of six variables is discussed in this section.

3.1. Project Participants (VO). Implementing techniques of integrated cost and schedule (EVMS) can be affectedly different depending on the stakeholders among project participants. It is known that EVMS for owners (VO1 or VO2 in Table 2) has the highest level of CAs (with less detail) while it should maintain thorough interrelationship between activities throughout the project life cycle (horizontal integration, OI in Table 3). For example, engineering activities need to be linked into procurement activities, and those procurement activities then clearly define their succeeding construction activities (EPC integration). Start-up and operation activities are also integrated in the same manner.

EVMS for engineering companies (VO3 in Table 2), equipment suppliers (VO4), or construction companies (VO5) has more detailed data with definite accuracy. For 
TABLE 2: EVMS variables and implementation alternatives.

\begin{tabular}{|c|c|c|}
\hline Variable (V-) & Alternatives & EVMS requirements (R-) \\
\hline VO: participant & $\begin{array}{l}\text { VO1: owner's PMO } \\
\text { VO2: EPC company's PMO } \\
\text { VO3: engineering company } \\
\text { VO4: equipment manufacturer } \\
\text { VO5: construction company } \\
\text { VO6: O\&M company }\end{array}$ & $\begin{array}{l}\text { (i) RO1: vertical level of details (LOD) } \\
\text { (ii) RO2: horizontal integration through project life cycle }\end{array}$ \\
\hline VB: project size (\$) & $\begin{array}{l}\text { VB1: budget }<10 \text { million } \\
\text { VB2: } 10 \leq \text { budget }<100 \text { million } \\
\text { VB3: } 100 \text { million } \leq \text { budget }<1 \text { billion } \\
\text { VB4: } 1 \text { billion } \leq \text { budget }\end{array}$ & (i) RB1: number of CAs \\
\hline $\begin{array}{l}\text { VD: project delivery } \\
\text { method (PDM) }\end{array}$ & $\begin{array}{l}\text { VD1: design-bid-build (DBB) } \\
\text { VD2: design-build (DB) } \\
\text { VD3: CM at risk (CMR) } \\
\text { VD4: design-build-maintain (DBM) } \\
\text { VD9: others }\end{array}$ & $\begin{array}{l}\text { (i) RD1: interorganizational integration through project } \\
\text { participants }\end{array}$ \\
\hline $\begin{array}{l}\text { VP: progress payment } \\
\text { method }\end{array}$ & $\begin{array}{l}\text { VP1: fixed price } \\
\text { VP2: unit price } \\
\text { VP3: cost reimbursable } \\
\text { VP9: others }\end{array}$ & $\begin{array}{l}\text { (i) RP1: Quantity take-off (QTO) in the planning phase } \\
\text { (preliminary estimate) }\end{array}$ \\
\hline $\begin{array}{l}\text { VM: progress measurement } \\
\text { method }\end{array}$ & $\begin{array}{l}\text { VM1: estimated percent complete } \\
\text { t VM2: earned value } \\
\text { VM3: physical measurement } \\
\text { VM9: others }\end{array}$ & $\begin{array}{l}\text { (i) RM1: accuracy versus effort required to measure progress } \\
\text { for each CA }\end{array}$ \\
\hline $\begin{array}{l}\text { VS: project management } \\
\text { strategies }\end{array}$ & $\begin{array}{l}\text { VS1: corporate strategy } \\
\text { VS2: technology strategy } \\
\text { VS3: project management strategy }\end{array}$ & $\begin{array}{l}\text { (i) RS1: functional integration } \\
\text { (ii) RS2: knowledge management }\end{array}$ \\
\hline
\end{tabular}

TABLE 3: EVMS implementing objectives and methods.

\begin{tabular}{|c|c|c|}
\hline Objectives (O-) & Methods & $\begin{array}{l}\text { Influencing } \\
\text { variables }\end{array}$ \\
\hline OI: integrating performance measures & $\begin{array}{l}\text { OI1: cost, time, and quality } \\
\text { OI2: life cycle (planning, EPC, start-up, and operation) } \\
\text { OI3: hierarchical schedules }\end{array}$ & \\
\hline OO: enhancing organizational capability & $\begin{array}{l}\text { OO1: planning capability as owner } \\
\text { OO2: project management capability as an EPC } \\
\text { OO3: organizational learning mechanism }\end{array}$ & $\begin{array}{l}\text { VO1 } \\
\text { VO2 } \\
\text { VB4 } \\
\text { VD4 }\end{array}$ \\
\hline OW: optimizing EVMS workload & $\begin{array}{l}\text { OW1: minimized additional data requirements } \\
\text { OW2: balanced data linkage and segment } \\
\text { OW3: maximized data utilization for analyses }\end{array}$ & $\begin{array}{l}\text { VD4 } \\
\text { VP1 } \\
\text { VM2 } \\
\text { VS- }\end{array}$ \\
\hline OC: augmenting cost engineering & $\begin{array}{l}\text { OC1: redesigning risk and cost management system } \\
\text { OC2: focused on cost engineering, not accounting } \\
\text { OC3: systemized project baseline }\end{array}$ & (Table 2) \\
\hline
\end{tabular}

example, general contractors (VO5) keep separate codes of account (COA) for labour, materials, and other cost types. Due to this detailed data structure, EVMS of engineers, suppliers, or contractors (VO3, VO4, and VO5) can be fully used for engineering analysis and simulations of on-going project as well as future projects.

3.2. Project Size (VB). It is not easy to categorize the range of construction project size in terms of monetary amount. NPP is one of the biggest capital projects as shown in the comparison with civil infrastructure cases in Table 1. EVMS for a mega-project implies using high-level CAs (with less detail) to be a manageable system. Though there is no proven practice for the relationship between the effective number of CAs and project monetary size, it was recommended by Jung et al. [13] that about one thousand CAs are most effective for the managers to intuitively interpret overall status of the project.

From a PMO's perspective, the monetary size of a megaproject makes it extraordinarily complex to manage cost and schedule in an integrated way unless the CAs are of very high level (less detailed LOD). For example, as shown in Project B of Table 1, a 20 billion dollar project with 1,400 CAs would have a CA (a CPM activity) that could cost about 
1.4 million dollars in average (20 billion dollars divided by 1,400 CAs). An important question needs to be addressed whether 1.4 million dollar CA can be adequate for effective management from technical and financial perspectives. In Table 1, it is clearly inferred that "Project B" may have bigger CAs than Projects $\mathrm{A}$ and $\mathrm{C}$ have (considering the project budget, duration, and project delivery method).

\subsection{Project Delivery Method (VD). Four major project deliv-} ery methods (PDM) in the construction industry include design-bid-build (DBB, B1 in Table 2), design-build (DB), construction management at risk (CMR), and design-buildmaintain (DBM) [15] As a different terminology of designbuild (DB), EPC (engineering, procurement, and construction) as a single contract is the typical PDM in the nuclear industry. It is notable that major equipment (e.g., turbine generator or nuclear steam supply system) vendors are often under multiprime contracts. Multiprime contract can be classified as a ramification of DBB.

However, under any sophisticated variation of PDM, the nature of nuclear construction process will stick to EPC principles in order to maximize the interactions between project participants. It is noteworthy that a research by Koppinen and Lahdenperä [15] proved DBM (VD4 in Table 2) as being the most effective project delivery method in terms of cost, schedule, and quality from the owners' perspective. The casecompany of this study was awarded a project (Project B in Table 2) under EPC plus operation contract, in other words, design-build-maintain (DBM, D4 in Table 2). EPC projects usually require higher level of CAs (bigger CAs with less detail) and strong interrelationship between EPC phases [16].

3.4. Progress Payment Method (VP). Among several different progress payment methods, including fixed price (lumpsum), unit price, and cost reimbursable, applying a specific method for a mega-construction project involves many issues such as politics, regulations, risk sharing, local economy, and management requirements. Despite "the highly uncertain nature of nuclear plant cost estimates" and "the changes toward more complex hybrid," fixed price contract serves as a base model in practice [17].

EVMS of the case-company in this paper uses lumpsum fixed price (VP1) contracts as a default type. However, limited numbers of activities (about 2\%) within the same project (Project B) are under cost-reimbursable or unit-price contracts (e.g., intake structure). Fixed price contracts for EPC (VD2 in Table 2) projects have difficulty in acquiring detailed work items and quantities for contractual purposes, especially in the planning stage before the design starts. This issue is directly related to setting up a project baseline and quantifying planed value (PV; budgeted cost work planned) and earned value (EV; budgeted cost work performed) for EVMS implementation.

3.5. Progress Measurement Method (VM). Three basic ways of measuring progress are estimate percent complete (VM1), earned value (VM2), and physical measurement (VM3). Criteria for selecting progress measurement methods include accuracy, frequency, and required effort for measuring the progress [10]. Physical measurement (VM1) for every single work item would obtain accurate progress information; however, it requires tremendous amount of efforts just for calculating project progress. Therefore, as for the variable of "progress measurement method" (VM), optimized tradeoffs between "accuracy and overhead efforts" should be thoroughly examined.

In order to select effective progress measurement methods, comprehensive considerations encompassing project size (VB), project delivery method (VD), progress payment method (VP), and management policies need to be considered. Of course, different methods can be used together within a project so that it can provide full flexibility in managing expensive human resources for progress measurement. The case-project in this study utilized the earned value (VM2) method for progress measurement as a prime method. The earned value (VM2) method used in the caseproject combined the principle of "apportioned relationships to discrete work" [8] and physical measurement (VM1) in order to reduce overhead effort from the owner's EVMS perspective.

3.6. Project Management Strategy (VS). Corporate strategy (VS1) at the highest level of an organization directs all business activities in an organization. The strategic significance of information systems (IS) has also been asserted by many researchers [18-21]. The traditional role of information systems has been to support business functions by replacing labor intensive transactions. However, as information systems have proliferated and become deeply interrelated with business processes, the role of IS has expanded further to supporting or even shaping corporate strategy [20,22]. As an IS as well as an advanced management methodology, EVMS has a strategic significance in terms of corporate strategy (VS1) and technology strategy (VS2). Particularly, under the expanding nuclear industry business environment, managing cost and schedule in an effective way can give competitive advantages to new entrants jockeying for position among current competitors.

In addition, due to the mega-size of the project and the technical complexity, nuclear power plant construction is performed by multiple specialty entities. Therefore, the vertical integration inside an EPC organization, which can be often observed in other industrial plant construction sectors, can be hardly achieved for NPP construction project. For this reason, indirect and contractual integration (e.g., by EVMS) among many parties is crucial for project NPP PMOs. EVMS needs to support the PMO in order to enhance technical and managerial leadership and in order to improve organizational learning as project strategy (VS3).

\section{PNS Formulating Methodology for NPP Project}

Based on the EVMS variables (V-) and requirements (R-) in Table 2, a methodology for formulating EVMS PNS for NPP construction was developed as depicted in Figure 1. For clear 


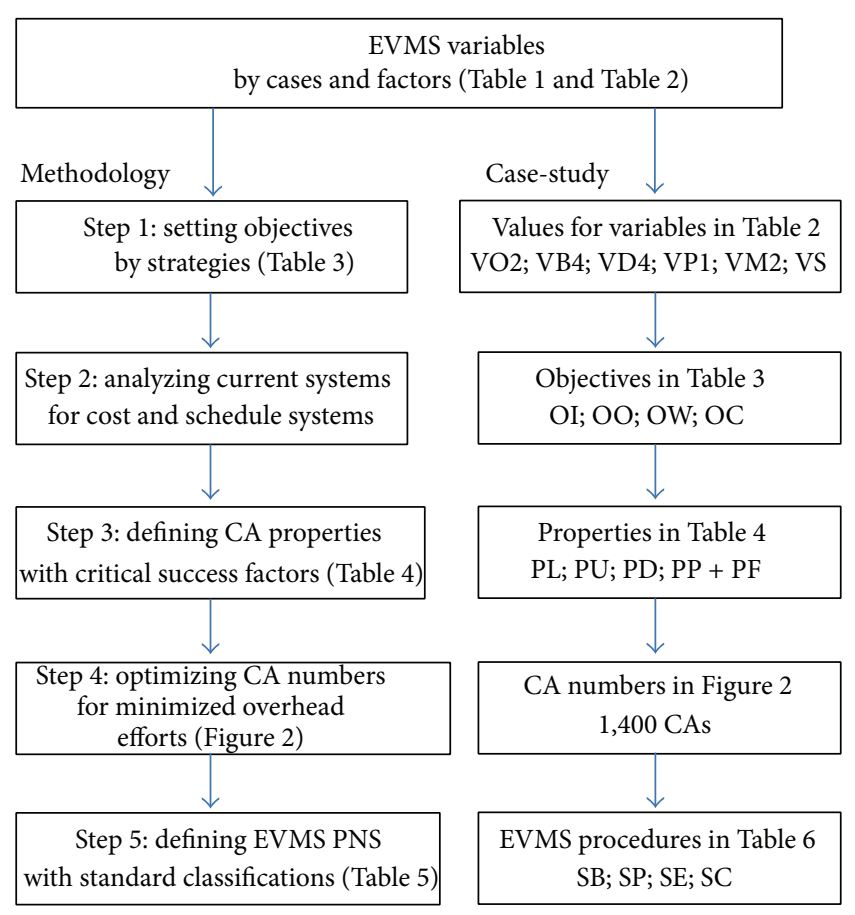

FIGURE 1: EVMS PNS formulating methodology and case-study.

understanding, this paper uses a case-company and a caseproject in order to illustrate the proposed step-by-step EVMS PNS formulating process.

4.1. The Case-Company and Case-Project. The case-company is a public owner that constructs and operates nuclear power plants in the Republic of Korea. However, this company has recently joined in global nuclear market as an EPC firm. This fact requires the case-company to perform an additional role as a DBM (design-build-maintain) project manager of an EPC firm (VO2) as well as an owner. The case-project (Project B) introduced in Table 1 is also used in order to validate the viability of proposed methodology. This study was conducted as part of an effort developing an organization-wide EVMS system from an owner's perspective (VO1 in Table 2) and from an EPC PMO's perspective (VO2).

In addition to the posture changes, the case-company needs to accelerate business process reengineering (BPR) effort in order to strengthen competitiveness under globalized market. EVMS was chosen as being a candidate BPR area. Technical capability throughout the project life cycle (i.e., planning, engineering, procurement, construction, start-up, and operation) is strongly stressed in this EVMS research (OO in Table 3). It is of great importance for the case-company because the company would execute multiple NPP construction projects in near future without having vertically integrated organizations.

4.2. Step 1: Setting Objectives for EVMS. Based on these backgrounds of the case-company, the research team has set up four major objectives, as described in Table 3, including "integrating performance measures," "enhancing organizational capability," "optimizing EVMS workload," and "augmenting cost engineering." Methods and techniques to achieve these objectives are also defined in Table 3.

"Integrating performance measures" (OI in Table 3) represents logical and physical interrelationship between data sets. EVMS control accounts (CAs) in this research will accommodate cost, time, and quality within a common denominator of work breakdown structure (WBS), so that three measures can be monitored and controlled in an integrated way (OI1). The data stored in CAs will be connected throughout the project life cycle (OI2). Finally, EVMS will physically interconnect four different levels of schedules (OI3), that is, milestone schedule, critical schedule, integrated control schedule, and detailed schedules. As described, the physical and logical interrelationships are balanced by having some strict linkage for integration and also by providing flexible segments [4] for systems effectiveness.

"Enhancing organizational capability" $(\mathrm{OO})$ concerns the organizational learning (as opposed to individual learning, OO3 in Table 3) by accumulating standardized knowledge especially in the area of cost and scheduling [23]. In order to accomplish this objective, several components (e.g., initial estimate and initial baseline) need to be standardized and automated [10]. This automation coupled with the management integration discussed in the first objective (OI) can effectively accumulate historical database. By doing so, well-organized and integrated data sets will facilitate the organizational learning for owner or EPC PMO's aspects (OO1 and $\mathrm{OO} 2$ ). Eventually, project management capabilities of all relevant participants will be improved by using those EVMS and reengineered management skills developed by the PMO.

The third objective is "optimizing EVMS workload" (OW). Excessive managerial effort for collecting and maintaining detailed data has been a major barrier to implementing this promising EVMS concept [2-4]. Fortunately, distinct characteristics of nuclear industry would make it more viable to implement EVMS because they have high level of perspective in managing projects. This paper added new features for minimizing EVMS workloads (OW1). An example is selected data linkages between related systems (OW2). Standardized dataset also utilizes abstracted information for effectiveness while keeping detailed enough outputs (OW3) for performance management analyses [23].

The final objective is "augmenting cost engineering" (OC) which focuses on cost engineering aspect. It is quite general that accounting systems, as opposed to cost engineering system, are more sophisticated and well utilized in owner organizations. Even though the case-company also has a welldefined accounting system, it does not suffice for engineering analyses in EVMS. Thus, this research proposed a new cost management procedure $(\mathrm{OC} 1$ and $\mathrm{OC} 2)$ that satisfies current organizational policies as well as future EVMS requirements. New system for managing budget and baseline (OC3) was also planned. The authors believe that reengineering cost management processes alone can dramatically benefit construction organizations if basic concepts of EVMS are properly applied. 
4.3. Step 2: Analysing Current Systems. The case-project has already utilized compressive and well-structured information systems for NPP construction projects. However, its systems focused on managerial functions for the owner's sake. Therefore, project management information systems (PMIS) of the case-project have quiet rough data from engineering or construction company's standpoint.

Every single function for construction project management is equally important. Among these construction management functions, however, the quality management is strongly stressed throughout the entire project life cycle in the nuclear industry. It was found that the case-company's existing system also put the highest priority in quality management systems. However, in the future, the company wants to enhance their capability in "cost management and design management" as well. This fact supports the company's strategy for expanding global market in the nuclear industry.

This emphasis on quality in current systems empowers the EVMS implementation more viably and effectively for nuclear plant construction because incorporating the integrated cost and schedule system onto current quality management system can minimize the overhead costs. For example, actual cost (AC; actual cost work performed) data for construction activities and CAs can be directly acquired from legacy inspection systems on sites.

Another good condition for EVMS is the existing schedule control systems. The case-company has a four-level hierarchical schedule control system, and new EVMS can be embedded into this system. Therefore, EVMS will not be a new additional one, but an effective supporting tool with minimum incremental investment.

4.4. Step 3: Defining CA Properties. As previously discussed, a control account (CA) in EVMS is a management control point where planned cost and schedule are compared against actual cost and schedule. Therefore, CA itself is an activity of network scheduling (e.g., CPM), and at the same time it is a cost account consisting of work items for that specific schedule activity. Three basic measures including planned value (PV), earned value (EV), and actual cost (AC) are used to analyse the cost and schedule performances within this common denominator of CA.

Defining CA properties for PNS will directly determine the level of details. This study identified five major CA properties including project life cycle (PL in Table 4), unit (PU), deliverable (PD), physical breakdown (PP), and functional breakdown (PF). These five different property classes are basically independent of each other, though some expressions may appear in more than one class. For the purpose of PNS development, these five properties may locate in different levels in terms of sequential hierarchy. The hierarchical positions can be determined by considering EVMS requirements listed in Table 2.

Grouping and classifying CAs by project life cycle (PL in Table 4) for EVMS purpose enables a primary mechanism to integrate project participants $(\mathrm{VO})$ under any type of project delivery methods (VD). This integration meets the EVMS requirement of integrating cost, time, and quality (OI1) throughout project life cycle (OI2) in order to enhance organizational capability as an owner (OO1) or as an EPC PMO (OO2) by an organizational learning mechanism (OO3).

For this purpose, project life cycle of an NPP project is defined into seven phases including planning (PRE), engineering (ENG), procurement (PRO), construction (CON), start-up and operation (OSS), fuel (FUL), and project management (PMO). Classification codes in the form of three digit alphabets are defined for PNS purpose as listed in the parentheses of respective phases. It is noteworthy that planning (PRE), fuel (FUL), and project management (PMO) are included within this property in order to constitute full range of project life cycle and to encompass full project cost into the monitoring system.

Facility unit (PF) has long been used as a major classifying property for PNS. It basically prescribes primary modules for generating electricity. For example, typical NPPs have two units of reactors and turbine generators. For this reason, this paper defined unit 1 (PU1), unit 2 (PU2), shared facilities (PU0) for PU1 and PU2, and generally supporting facilities and services (PU9). For the cases with more than two units, unit 3 (PU3), unit 4 (PU4), and so forth can be assigned. Single digit number is assigned as PNS codes, $0,1,2$, and 9, respectively, as listed in Table 4.

The deliverable (PD) as a PNS property is a very novel approach in this paper, and rationale behind utilizing PD as a PNS property is to optimize EVMS workloads (OW). Classifications by the same type of deliverable (PD) also clearly indicate different types of CAs to be linked (e.g., specifications required to procurement process) for effective manipulation (OW2). Even within the same type of engineering documents, as-built documents are separated in order to maximize the discrete characteristics of long lead item (OW3). For example, separating as-built drawings and relevant documents altogether from an engineering CA makes it much shorter activity, so that the status of that specific CA can be clearly monitored by whether it is completed or not.

Physical breakdown (PP in Table 4) and functional breakdown (PF) are the most often used properties for the purpose of numbering all different types of construction management functions including design management, estimating, scheduling, cost control, quality management, materials management, and even accounting. PP classifications are building codes (BLDG, PP1) and physical breakdown structure (PBS, PP2); both of them are already well defined as company-wide standards. PF classifications as the casecompany's standards include functional breakdown structure (FBS, PF1), construction packages (CP, PF2), and organizational breakdown structure (OBS, PF3). FBS (PF1) is more often used for engineering and procurement $\mathrm{CAs}$, while $\mathrm{CP}$ $(\mathrm{PF} 2)$ is frequently used for construction CAs.

4.5. Step 4: Optimizing CA Numbers. Every single CA may have different size in terms of cost and time. Having more detailed (lower level) CAs for a project would enhance the accuracy of measuring project performances; however, it would require far more overhead efforts in collecting and 
TABLE 4: PNS properties of control account (CA).

\begin{tabular}{|c|c|c|c|}
\hline Property (P-) & Value & Code & Classifications \\
\hline PL: project life cycle & $\begin{array}{l}\text { PL1: planning } \\
\text { PL2: engineering } \\
\text { PL3: procurement } \\
\text { PL4: construction } \\
\text { PL5: start-up and operation } \\
\text { PL6: fuel } \\
\text { PL7: project management }\end{array}$ & $\begin{array}{l}\text { PRE } \\
\text { ENG } \\
\text { PRO } \\
\text { CON } \\
\text { OSS } \\
\text { FUL } \\
\text { PMO }\end{array}$ & $\begin{array}{l}\text { EVMS } \\
\text { standards }\end{array}$ \\
\hline PU: facility unit & $\begin{array}{l}\text { PU0: shared } \\
\text { PU1: unit } 1 \\
\text { PU2: unit } 2 \\
\text { PU9: general requirements }\end{array}$ & $\begin{array}{l}0 \\
1 \\
2 \\
9\end{array}$ & $\begin{array}{l}\text { Company } \\
\text { general } \\
\text { standards }\end{array}$ \\
\hline PD: deliverable type & $\begin{array}{l}\text { PDP: planning documents } \\
\text { PDD: drawings } \\
\text { PDE: specifications } \\
\text { PDR: report } \\
\text { PDC: combined } \\
\text { PDL: as-built } \\
\text { PDN: NSSS } \\
\text { PDT: turbine generator } \\
\text { PDB: BOP } \\
\text { PDO: construction } \\
\text { PDA: start-up assistance } \\
\text { PDS: start-up } \\
\text { PDM: operation and maintenance } \\
\text { PDU: training } \\
\text { PDI: ICT } \\
\text { PDF: fuel } \\
\text { PDZ: project management }\end{array}$ & $\begin{array}{l}\text { P } \\
D \\
\text { E } \\
\text { R } \\
\text { C } \\
\text { L } \\
\text { N } \\
\text { T } \\
\text { B } \\
\text { O } \\
\text { A } \\
\text { S } \\
\text { M } \\
\text { U } \\
\text { I } \\
\text { F } \\
Z\end{array}$ & $\begin{array}{l}\text { EVMS } \\
\text { standards }\end{array}$ \\
\hline PP: physical breakdown & $\begin{array}{l}\text { PP1: building (BLDG) } \\
\text { PP2: physical breakdown structure (PBS) }\end{array}$ & $\begin{array}{l}3 \text { digits } \\
3 \text { digits }\end{array}$ & $\begin{array}{l}\text { Company } \\
\text { general } \\
\text { standards }\end{array}$ \\
\hline PF: functional breakdown & $\begin{array}{l}\text { PF1: functional breakdown structure (FBS) } \\
\text { PF2: construction packages (CP) } \\
\text { PF3: organization breakdown structure (OBS) }\end{array}$ & $\begin{array}{l}4 \text { digits } \\
4 \text { digits } \\
1 \text { digit }\end{array}$ & $\begin{array}{l}\text { Company } \\
\text { general } \\
\text { standards }\end{array}$ \\
\hline
\end{tabular}

analysing those performance data. Therefore, the number of CAs is the prime barometer for overhead amount required in EVMS [4], and trade-offs between accuracy and overhead efforts need to be optimized (OW1). In order to address this issue, this study utilized the concept of flexible work breakdown structure (WBS) proposed by Jung and Woo [4]. Namely, according to varying managerial importance of each $\mathrm{CA}$, the size of CAs on the same hierarchical level can be different. In order to effectively handle this manipulation, it should be possible that different PNS structures are allowed within the exactly same level by assigning different properties in their PNS sequence. In addition to these issues of accuracy and overhead efforts, CAs need to be a tool for embedding historical knowledge (OO1) to enhance organizational capability in planning (OO1) and controlling (OO2).

Iterative simulations with painstaking discussions had been performed by the authors and industry practitioners through several workshops in order to figure out the most optimized CAs meeting all objectives listed in Table 3. Finally, the authors generated about 1,400 CAs by regrouping 18,000 of CPM schedule activities of the case-project. The total budget for these 18,000 activities is about 20 billion dollars as listed in Case B in Table 1. In this process, every single possible interrelationship between four major objectives in Table 4 and five major properties in Table 5 is evaluated in order to optimize the number of CAs.

Figure 2 illustrates an overview of the 1,400 CAs in terms of budget size and duration. Engineering (ENG), start-up and operation (OSS), construction (CON), procurement (PRO), planning (PRE), project management and indirect costs (PMO), and fuel (FUL) count for $27.46 \%, 26.76 \%$, $24.01 \%, 20.21 \%, 0.63 \%, 0.49 \%$, and $0.42 \%$, respectively, in terms of number of CAs. Among the project life cycle (PL), engineering phase (ENG) has the most CAs (27.46\%). It means that the case-study PMO wanted to have better control over engineering activities. Within these engineering (ENG) CAs, specifications (PDE) have the most CAs; it counts for $14.44 \%$ of entire 1,400 CAs. Again, it shows that the PMO has a managerial emphasis especially on managing engineering firm's specifications. It also implies that the PMO wants to 
TABLE 5: PNS structure for NPP EVMS.

\begin{tabular}{|c|c|c|c|c|c|}
\hline Description & $\begin{array}{c}\text { PL } \\
\text { (3 digits) }\end{array}$ & $\begin{array}{c}\text { PU } \\
\text { (1 digit) }\end{array}$ & $\begin{array}{c}\text { PD } \\
\text { (1 digit) }\end{array}$ & $\begin{array}{c}\mathrm{PP}+\mathrm{PF} \\
(3 \sim 5 \text { digits })\end{array}$ & $\begin{array}{c}\text { Item level } \\
\text { classifications }\end{array}$ \\
\hline \multicolumn{6}{|l|}{ Planning } \\
\hline Planning & PRE & 9 & $\mathrm{P}$ & Serial (3) & Nonstandard \\
\hline \multicolumn{6}{|l|}{ Engineering } \\
\hline Drawing & ENG & $0 \sim 9$ & $\mathrm{D}$ & BLDG (3) + OBS (1) & \\
\hline \multirow{2}{*}{ Specs } & ENG & $0 \sim 9$ & $\mathrm{E}$ & $\mathrm{CP}(4)$ & \\
\hline & ENG & $0 \sim 9$ & $\mathrm{E}$ & FBS (4) & \\
\hline Report & ENG & $0 \sim 9$ & $\mathrm{R}$ & PBS (3) & \\
\hline \multirow[t]{2}{*}{ Combined } & ENG & $0 \sim 9$ & $\mathrm{C}$ & PBS (3) & \\
\hline & ENG & $0 \sim 9$ & $\mathrm{~L}$ & BLDG (3) & \\
\hline \multirow[t]{3}{*}{ As-built } & ENG & $0 \sim 9$ & $\mathrm{~L}$ & PBS (3) & \\
\hline & ENG & $0 \sim 9$ & $\mathrm{~L}$ & $\mathrm{CP}(4)$ & \\
\hline & ENG & $0 \sim 9$ & $\mathrm{~L}$ & OBS (4) & \\
\hline \multicolumn{6}{|l|}{ Procurement } \\
\hline NSSS & PRO & $0 \sim 9$ & $\mathrm{~N}$ & & Nonstandard \\
\hline $\mathrm{T} / \mathrm{G}$ & PRO & $0 \sim 9$ & $\mathrm{~T}$ & & Nonstandard \\
\hline BOP & PRO & $0 \sim 9$ & $\mathrm{~B}$ & FBS (4) & \\
\hline \multicolumn{6}{|l|}{ Construction } \\
\hline Construction pkgs & $\mathrm{CON}$ & $0 \sim 9$ & $\mathrm{O}$ & $\operatorname{BLDG}(3)+\mathrm{CP}(2)$ & \\
\hline Start-up assistance & $\mathrm{CON}$ & $0 \sim 9$ & A & PBS (3) & \\
\hline \multicolumn{6}{|l|}{ Start-up } \\
\hline Start-up & OsS & $0 \sim 9$ & S & PBS (3) & \\
\hline $\mathrm{O} \& \mathrm{M}$ & OSS & $0 \sim 9$ & M & PBS (3) & \\
\hline Training & OSS & $0 \sim 9$ & $\mathrm{U}$ & PBS (3) & \\
\hline ICT & OsS & $0 \sim 9$ & I & PBS (3) & \\
\hline Fuel & FUL & $0 \sim 9$ & $\mathrm{~F}$ & Serial (3) & Nonstandard \\
\hline Project management & $\mathrm{PMO}$ & 9 & $\mathrm{Z}$ & Serial (3) & Nonstandard \\
\hline
\end{tabular}

have a mechanism to accumulate knowledge and experience of engineering specifications (PDE) even though this task is currently outsourced to engineering companies.

4.6. Step 5: Defining EVMS PNS. Based on studies of Steps 1 through 4, a PNS for NPP EVMS was developed as described in Table 5. The sequence of the PNS is composed of project life cycle (PL in Table 4), facility unit (PU), deliverable type (PD), and finally a combination of physical breakdown (PP) and functional breakdown (PF).

For example, a CA of excavation and backfill (construction package code $\mathrm{C}$ ) for reactor containment building (building code RCB) of unit 1 is encoded as "CON1ORCBC1" (highlighted within a red box in Figure 3), where the first three digits mean PL code of construction stage (CON). Next one digit code (1) is for facility unit 1, and following one digit indicates deliverable type for construction packages (O). From sixth digit, three letters specify a building as a physical breakdown (RCB), and finally the last two digits show construction packages as a functional breakdown (C1) of excavation and backfill.

Note that the first five digits for PL, PU, and PD in Table 5 have a common structure, strictly applied to all 1,400 CAs in the same manner. However, beginning from the sixth digit (for $\mathrm{PP}+\mathrm{PF}$ ), the numbering sequence and methods are different based on the characteristics of each category. The concept of "flexible WBS" proposed by Jung and Woo [4] was applied, and this flexibility enables effective utilization (OW in Table 1) of overhead efforts required to implement EVMS in practice.

Regardless of this CA numbering, every subactivity assigned under a specific CA has an identification number that follows a different rule by project-standard scheduling procedure. In other words, several CPM activities, which are numbered independently by different numbering systems (scheduling function), are included within the CA example 


\begin{tabular}{lcc}
\hline \multirow{2}{*}{ Desc } & \multicolumn{2}{c}{ Number (\%) } \\
& CA & Activity \\
\hline Planning & 0.63 & 0.05 \\
Planning (P) & 0.63 & 0.05 \\
Engineering & 27.46 & 50.85 \\
Drawing (D) & 7.11 & 25.17 \\
Specs (E) & 14.44 & 3.28 \\
Report (R) & 0.42 & 2.66 \\
Combined (C) & 3.24 & 6.81 \\
As-built (L) & 2.25 & 12.93 \\
Procurement & 20.21 & 8.40 \\
NSSS (N) & 4.15 & 5.26 \\
T/G (T) & 3.03 & 0.21 \\
BOP (B) & 13.03 & 2.93 \\
Construction & 24.01 & 24.06 \\
Construction pkgs (O) & 22.96 & 20.48 \\
Start-up assistance (A) & 1.06 & 3.58 \\
Start-up & 26.76 & 15.42 \\
Start-up (S) & 26.55 & 14.65 \\
O\&M & 0.07 & 0.16 \\
Training (U) & 0.07 & 0.32 \\
ICT (I) & 0.07 & 0.29 \\
Fuel & 0.42 & 1.18 \\
Fuel (F) & 0.42 & 1.18 \\
PM and indirect costs & 0.49 & 0.04 \\
PM and indirect (Z) & 0.49 & 0.04 \\
\hline Total & 100 & 100 \\
\hline
\end{tabular}

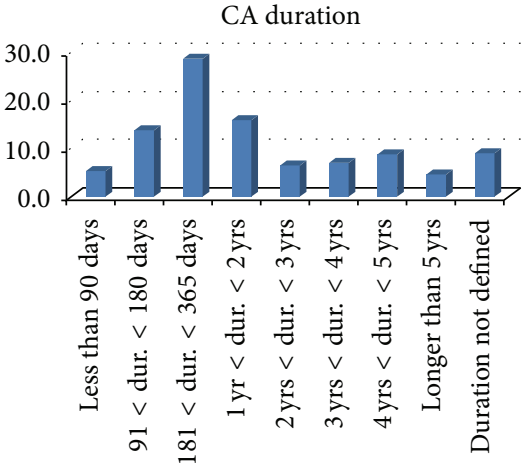

(\%)

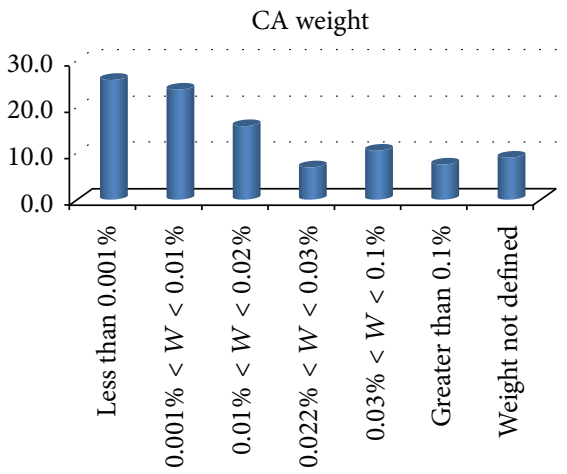

(\%)

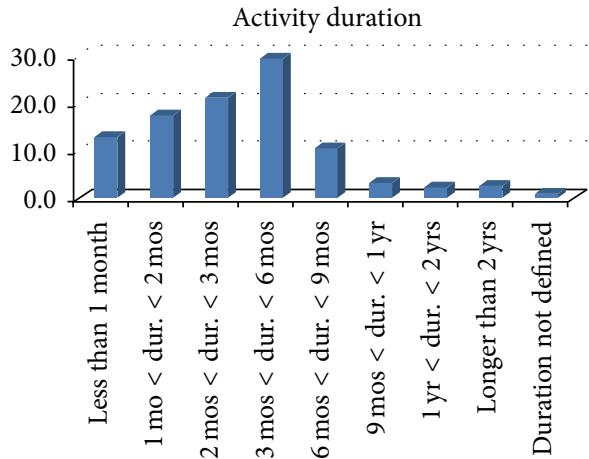

(\%)

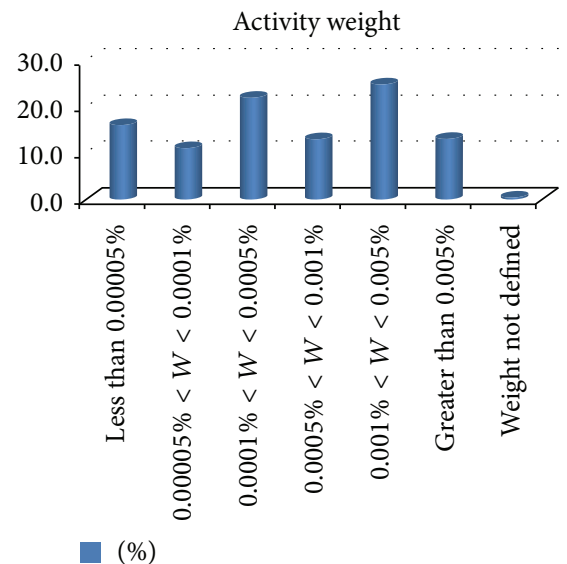

Figure 2: Number of CAs of case-project.
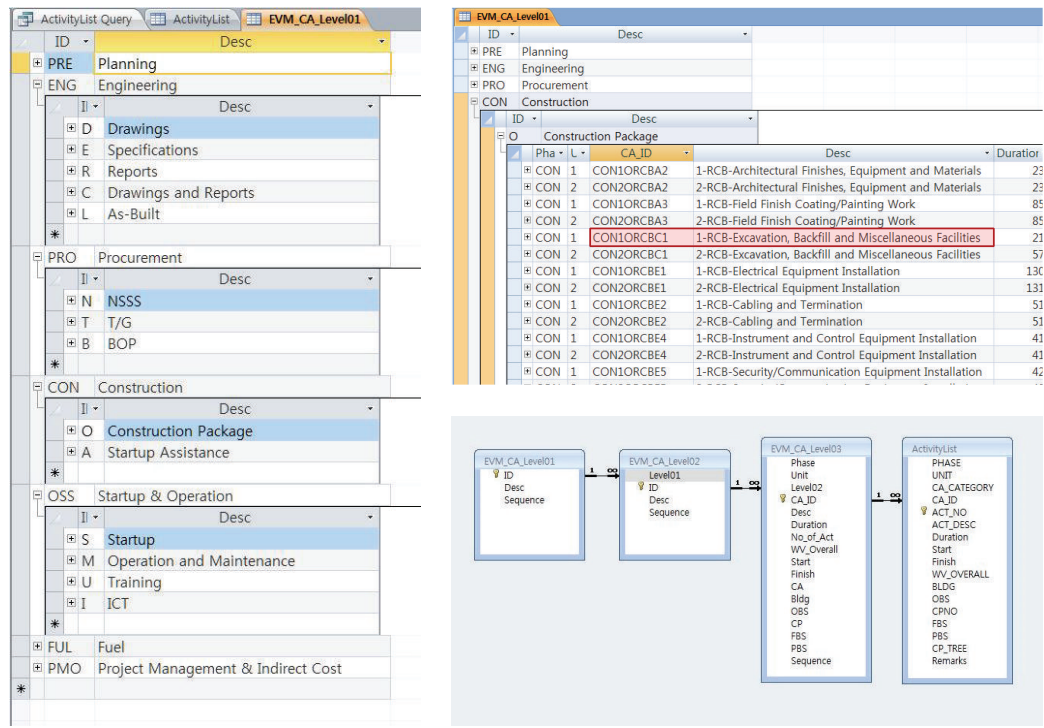

FIgURE 3: Relational database of NPP EVMS CAs.

of CON1ORCBC1 as subordinate components. Therefore, EVMS PNS is another querying mechanism to retrieve important information.

EVMS numbering system in Table 5 and in Figure 3 uses current standard classifications of case-company for the PNS elements of BLDG, CP, PBS, FBS, and OBS (PP and PF properties in Table 5). However, classifications for properties of PL, PU, and PD are newly defined for EVMS implementation. Nevertheless, these classifications do not interfere with existing business functions such as scheduling, 
TABLE 6: NPP EVMS standard procedures for system development.

\begin{tabular}{lll}
\hline $\begin{array}{l}\text { Description } \\
\text { (S-) }\end{array}$ & Method and procedure & Technique \\
\hline $\begin{array}{l}\text { Budget } \\
\text { (SB) }\end{array}$ & $\begin{array}{l}\text { SBD: standard estimate database } \\
\text { SBE: project estimate } \\
\text { SBB: project budget }\end{array}$ & $\begin{array}{l}\text { (i) Knowledge embedding } \\
\text { (ii) Self-evolving } \\
\text { (iii) Future extension to BIM }\end{array}$ \\
\hline PV & SPA: top-down Qty based assignment & (i) Earned standards \\
(SP) & SPW: standard weighted milestones & (ii) Simplified resources \\
\hline EV & SEV: rolling up EVs based on Qty & (i) Target progress concept \\
(SE) & SES: existing scheduling system & (ii) Activities not connected to cost \\
\hline AC & SAC: decomposed cost from ERP & (i) Quantity and resource related \\
(SA) & SAA: existing accounting system (ERP) & (ii) Generic accounting system \\
\hline
\end{tabular}

cost control, or estimating. Self-evolving mechanism by continuously updating and improving the standard CAs for the case-company is also under development by the authors.

Figure 3 depicts the actual entity-relationship diagram (ERD) of EVMS relational database. Left part shows classification by PL (3 digits) and PD (1 digit) in Table 5. Upper-right snapshot presents CA packages (e.g., "CON1ORCBCl”).

\section{EVMS Procedure for Systems Development}

Total number of CAs in the case-project is about 1,400, which is concise enough to manage the project at a glance [13] and, at the same time, is detailed enough to encompass different types of work packages in order to meet the objectives defined in Table 3. As discussed in previous sections, several different criteria including total number, monetary size, duration, and similarity are fully considered in CA grouping process to enhance organizational capability.

An EVMS procedure requires setting up a project baseline first by assigning every single cost item into scheduling activities. After baseline being approved, planned value (PV), formerly known as budget cost work planned (BCWP), for each CA, is calculated as a target progress. Earned value (EV), also known as budget cost work performed (BCWP), for each $\mathrm{CA}$, is appraised as the progress for each time frame. Finally, actual cost (AC) is then summarized and compared with EV. By comparing these three values of $\mathrm{PV}, \mathrm{EV}$, and $\mathrm{AC}$ for each $\mathrm{CA}$, many different indices including schedule variance (EV$\mathrm{PV}$ ) and cost variance (EV-AC) are provided for monitoring and decision making processes.

EVMS procedures for NPP construction developed in this study are briefly introduced based on planned value (PV), earned value (EV), and actual cost (AC).

An EVMS requires an advanced budgeting system as a prerequisite. This study defined three groups of budgeting systems (SB in Table 6) for the case-company including systems for standard estimate database (SBD), project estimate (SBE), and project budget (SBB). Self-evolving and knowledge embedding mechanisms are proposed to facilitate the organizational learning process in the standard estimating database (requirement RS2 in Table 2). Officially approved internal project budget (SBB) will be used as a base for project baseline that will determine planned value (PV) in turn. It was designed to issue the project budget in the early stage well before detailed design and estimating start.

PV for each CA can be calculated by adding all PVs of subordinate activities. Basic rules of calculating PVs in this study include top-down allocation of weights, temporal dissemination by historical earned standards, and overall adjustments [24]. Some CAs may have not enough details in the early stage; however, every single CA should be defined with quantities and amount of major work items (requirement RP1 in Table 2).

EV for each activity will be calculated by comparing the quantity of actual budgeted cost work performed (BCWP) against the total quantity. Note that the "CA total quantity" here may be varying as project proceeds, and "quantities" are from representing work items only. Rationale behind using "quantities" instead of "amount" is that initial top-down allocation (SPA) may have no detailed information at the time of baseline and PV setting. Therefore, fixed total amount for CAs can stabilize EVMS implementation under possible changes of quantity.

In order to minimize the tolerance between planned and final PV values, major work items and their weighted milestones are predefined in the system (SPW). "Earned standards" based on historical database were chosen as being methodology to solve this problem. These weighted milestones are directly used to calculate EV for each activity. Summary of activities' EV within a CA will automatically determine the EV for that $\mathrm{CA}$.

Finally, AC is collected by CAs. Cost data from accounting systems (ERP system in Table 6, SAA) will be decomposed into the CA level. These decomposed cost data will be linked to resource data in order to provide valuable information for cost engineering as well as standard estimate database (SBD in Table 6). However, decomposing ERP data (SAA) to cost control system (SAC) requires huge managerial efforts. An automated way to decompose cost data is now under development by using proposed EVMS PNS.

Proposed numbering systems (PNS), procedures, and also techniques are designed in order to clearly monitor cost and schedule of on-going projects and also in order to 
accumulate historical database. A full-scale, web-based pilot system is under development by the case-company. Details of pilot EVMS system will be introduced in future publications. It is also planned to explore the integration of these systems with 3D-CAD data (BIM applications), so that automated updating and concurrent engineering can be achieved.

\section{Conclusions}

Work packaging with a project numbering system (PNS) is important task for construction planning, and it needs to incorporate distinct characteristics of each project. Therefore, WBS has been recognized as being unique one for each project. Nevertheless, considerations and variables for formulating WBS may have common principles. In this sense, comprehensive variables and their influence on WBS formulation have been systematically investigated in this paper.

This study proposed a procedural methodology for formulating a PNS for NPP EVMS. Issues of performance improvements and competitive advantages under different project conditions are incorporated within proposed EVMS variables. A systematic approach to integrate the EVMS requirements is also developed and validated by applying to a case-project of NPP construction.

In a NPP case-project, under ever-changing construction environment, owners and EPC PMOs tend to be more actively involved in their construction projects. In order to have managerial capabilities as well as technical capabilities in terms of oversight management, the owners and EPC PMOs need to have more sophisticated systems to monitor overall construction project throughout entire project life cycle. EVSM provides them with an effective tool. Nevertheless, it was pointed out that EVMS optimization was required to minimize the overhead efforts.

For the purpose of maximizing benefits from the NPP EVMS, strategic requirements are identified first. The project delivery method (VD in Table 2) and PMO strategy were considered as being the most important variables for EVMS development. Based on the variable investigations, EVMS objectives and methods were developed. These managerial and technical requirements were fully incorporated in the PNS definition process.

It was observed that distinct characteristics of nuclear power plant construction make the PMO's EVMS implementation more viable and effective than any other types of construction projects. The advantages of solid quality management systems already linked to scheduling systems help the EVMS to be more capable. High-level oversight management requirements for mega-projects have also motivated the needs for EVMS.

As a demand pull, strategic needs for enhancing cost and schedule control capabilities under globalized competition require the EPC firms to furnish EVMS techniques. Technology push, by recent advancement of data acquisition technology (DAT) and building information modelling (BIM), also gives better opportunities to EVMS implementation. Finally, the authors could recognize that EVMS implementation can be very successful if it is properly optimized in terms of reengineering, workloads, and knowledge embedding.

\section{Conflict of Interests}

The authors declare that there is no conflict of interests regarding the publication of this paper.

\section{Acknowledgments}

This study was supported by "Basic Science Research Program" through the National Research Foundation of Korea (NRF) funded by the Ministry of Science, ICT, and Future Planning (MSIP) under Grant no. 2014R1A2A2A01006984. It was also partly supported by the Korean Ministry of Knowledge and Economy (MKE) under Grant no. 2011T100200143. Active participations from Korea Hydro and Nuclear Power Co., Ltd. (KHNP) and KEPCO E\&C Co., Inc. are also gratefully acknowledged.

\section{References}

[1] M. Richardson, "Nuclear plant construction up; South Korea challenging market," The Japan Times Online, 2010, http://search .japantimes.co.jp/cgi-bin/eo20100201mr.htm.

[2] W. J. Rasdorf and O. Y. Abudayyeh, "Cost- and schedulecontrol integration. Issues and needs," Journal of Construction Engineering and Management ASCE, vol. 117, no. 3, pp. 486-502, 1991.

[3] M. Z. M. Deng and Y. E. Hung, "Integrated cost and schedule control: Hong Kong perspective," Project Management Journal, vol. 29, no. 4, pp. 43-49, 1998.

[4] Y. Jung and S. Woo, "Flexible work breakdown structure for integrated cost and schedule control," Journal of Construction Engineering and Management ASCE, vol. 130, no. 5, pp. 616-625, 2004.

[5] Y. Jung, Y. Kim, M. Kim, and T. Ju, "Concept and structure of parametric object breakdown structure (OBS) for practical BIM," Korean Journal of Construction Engineering and Management, vol. 14, no. 3, pp. 88-96, 2013.

[6] N. N. Eldin, "Measurement of work progress: quantitative technique," Journal of Construction Engineering and Management, vol. 115, no. 3, pp. 462-474, 1989.

[7] N. N. Eldin, "Management of engineering/design phase," Journal of Construction Engineering and Management, vol. 117, no. 1, pp. 163-175, 1991.

[8] Q. W. Fleming and J. M. Koppleman, Earned Value Project Management, Project Management Institute, Upper Darby, Pa, USA, 1996.

[9] Electronic Industries Alliance (EIA), "Earned value management systems," EIA Publication ANSI/EIA-748-1998, EIA, Arlington, Va, USA, 1998.

[10] Y. Jung and S. Kang, "Knowledge-based standard progress measurement for integrated cost and schedule performance control," Journal of Construction Engineering and Management, vol. 133, no. 1, pp. 10-21, 2007.

[11] Project Management Institute (PMI), A Guide to Project Management Body of Knowledge, Project Management Institute, Upper Darby, Pa, USA, 1996. 
[12] Construction Industry Institute (CII), Research Team 272, WorkFace Planning; From Design through Site Execution, 2013, https://www.construction-institute.org/.

[13] Y. Jung, H. Park, and J. Y. Moon, "Requirements for integrated cost and schedule control: process redesign guidelines for the Korean contractors," Working Paper 25, Construction \& Economy Research Institute of Korea (CERIK), Seoul, Republic of Korea, 2000.

[14] Y. Jung and M. Joo, "Building information modelling (BIM) framework for practical implementation," Automation in Construction, vol. 20, no. 2, pp. 126-133, 2011.

[15] T. Koppinen and P. Lahdenperä, "Realized economic efficiency of road project delivery systems," Journal of Infrastructure Systems, vol. 13, no. 4, pp. 321-329, 2007.

[16] Y. Jung, "Integrated cost and schedule control: variables for theory and implementation," in Proceedings of the Construction Research Congress, pp. 1-10, ASCE, San Diego, Calif, USA, 2005.

[17] T. Flaherty, "Navigating nuclear risks: new approaches to contracting in a post-turnkey world," Public Utilities Fortnightly, pp. 39-45, 2008.

[18] J. Y. Bakos and M. E. Treacy, "Information technology and corporate strategy: a research perspective," MIS Quarterly: Management Information Systems, vol. 10, no. 2, pp. 107-119, 1986.

[19] J. C. Henderson and N. Venkatraman, "Strategic alignment: leveraging information technology for transforming organizations," IBM Systems Journal, vol. 32, no. 1, pp. 4-16, 1993.

[20] Y. Jung and G. E. Gibson Jr., "Planning for computer integrated construction," Journal of Computing in Civil Engineering, vol. 13, no. 4, pp. 217-225, 1999.

[21] Y. Jung, S. Chin, and K. Kim, "Informatization index for the construction industry," Journal of Computing in Civil Engineering, vol. 18, no. 3, pp. 267-276, 2004.

[22] Y. Jung, S. Kang, Y.-S. Kim, and C. Park, "Assessment of safety management information systems for general contractors," Safety Science, vol. 46, no. 4, pp. 661-674, 2008.

[23] Y. Jung, "Automated front-end planning for cost and schedule: variables for theory and implementation," in Proceedings of the Architectural Engineering National Conference, pp. 1-10, ASCE, Denver, Colo, USA, 2008.

[24] B.-S. Moon, A study on the application of EVMS to nuclear power plant construction project [M.S. thesis], Soongsil University, Seoul, Republic of Korea, 2009. 


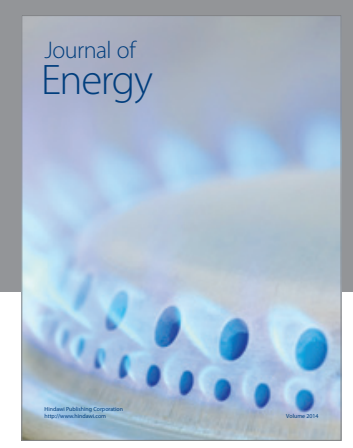

Journal of

Industrial Engineering
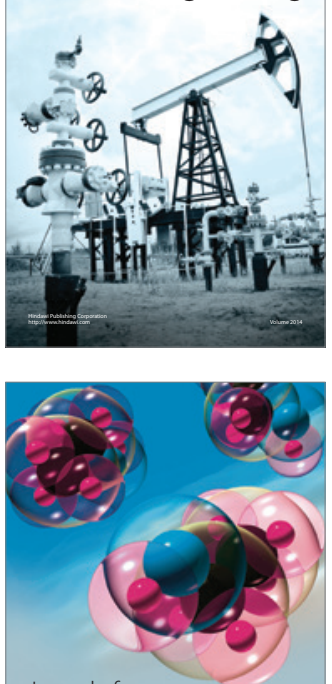

Fuels
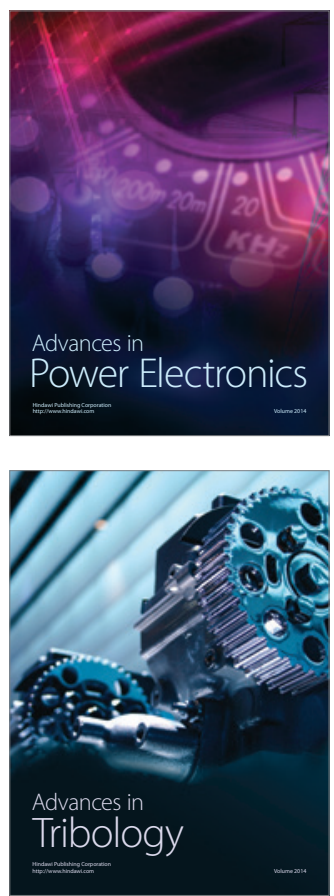

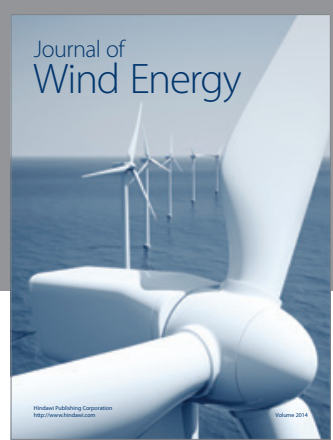

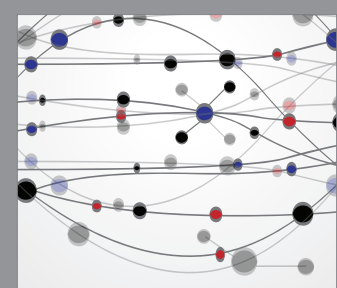

The Scientific World Journal

Submit your manuscripts at http://www.hindawi.com

Journal of

Structures
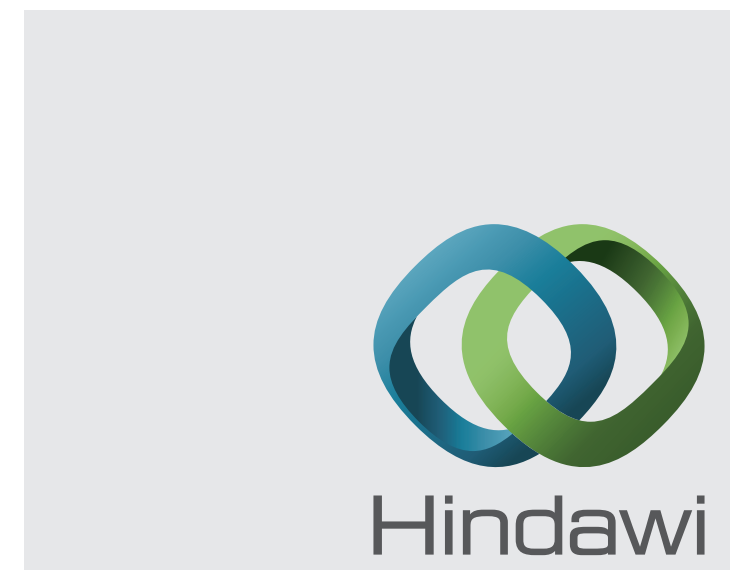

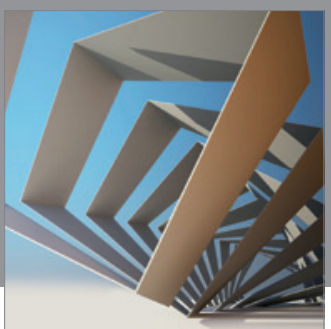

Rotating

Machinery
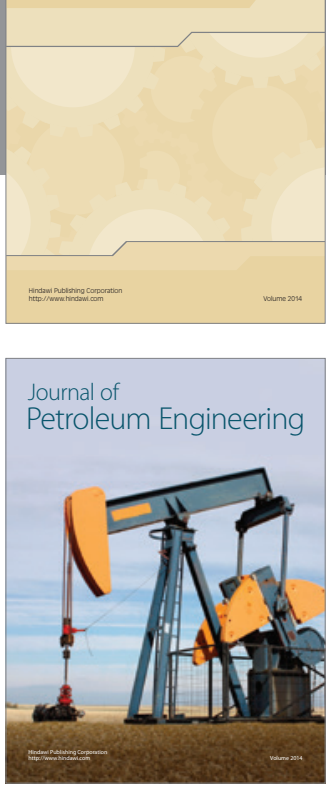

Journal of

Solar Energy
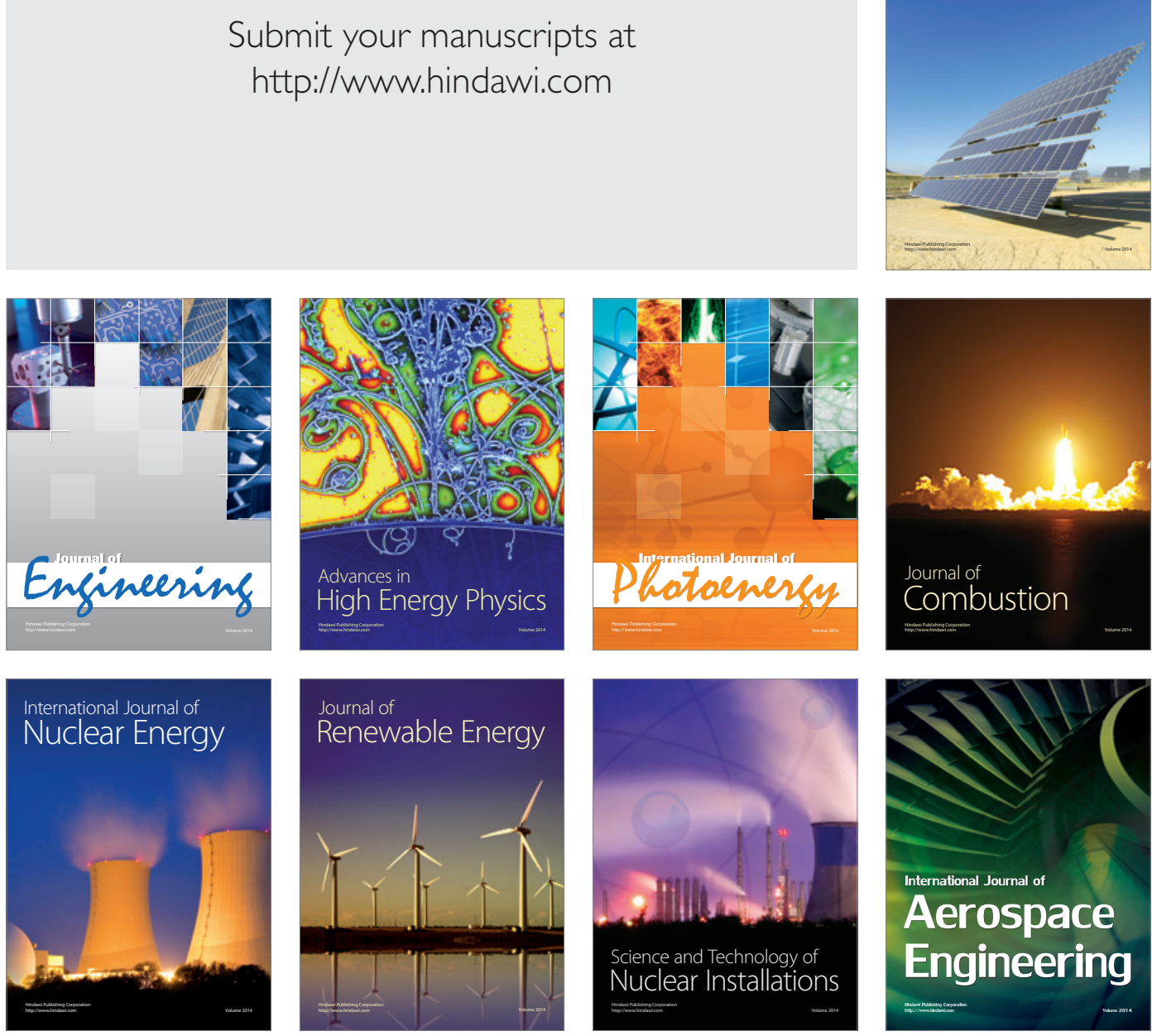